\title{
Gestural communication of the gorilla (Gorilla gorilla): repertoire, intentionality and possible origins
}

\author{
Emilie Genty · Thomas Breuer · Catherine Hobaiter • \\ Richard W. Byrne
}

Received: 14 July 2008/Revised: 12 December 2008/Accepted: 8 January 2009/Published online: 1 February 2009

(C) Springer-Verlag 2009

\begin{abstract}
Social groups of gorillas were observed in three captive facilities and one African field site. Cases of potential gesture use, totalling 9,540, were filtered by strict criteria for intentionality, giving a corpus of 5,250 instances of intentional gesture use. This indicated a repertoire of 102 gesture types. Most repertoire differences between individuals and sites were explicable as a consequence of environmental affordances and sampling effects: overall gesture frequency was a good predictor of universality of occurrence. Only one gesture was idiosyncratic to a single individual, and was given only to humans. Indications of cultural learning were few, though not absent. Six gestures appeared to be traditions within single social groups, but overall concordance in repertoires was almost as high between as within social groups. No support was found for the ontogenetic ritualization hypothesis as the chief means of acquisition of gestures. Many gestures whose form ruled out such an origin, i.e. gestures derived from species-typical displays, were used as intentionally and almost as flexibly as gestures whose form was consistent with learning by ritualization. When using both classes of gesture, gorillas paid specific attention to the attentional state of their audience. Thus, it would be
\end{abstract}

E. Genty $\cdot$ C. Hobaiter $\cdot$ R. W. Byrne $(\varangle)$

Centre for Social Learning and Cognitive Evolution and Scottish

Primate Research Group, School of Psychology,

University of St Andrews, Fife KY16 9JP, Scotland, UK

e-mail: rwb@st-andrews.ac.uk

T. Breuer

Department of Primatology,

Max Planck Institute for Evolutionary Anthropology,

Deutscher Platz 6, 04103 Leipzig, Germany

T. Breuer

Mbeli Bai Study, Wildlife Conservation Society,

Congo Program, BP 14537, Brazzaville, Republic of Congo unwarranted to divide ape gestural repertoires into 'innate, species-typical, inflexible reactions' and 'individually learned, intentional, flexible communication'. We conclude that gorilla gestural communication is based on a speciestypical repertoire, like those of most other mammalian species but very much larger. Gorilla gestures are not, however, inflexible signals but are employed for intentional communication to specific individuals.

Keywords Great ape - Gesture - Audience effects . Flexibility $\cdot$ Ontogeny

\section{Introduction}

Fifty years of modern research on the vocalizations of monkeys and apes has revealed many fascinating aspects of animal cognition, but has shown that the auditory communication systems of non-human primates are very unlike human language (Cheney and Seyfarth 1996; Hauser et al. 2002). Syntax is missing (but see Arnold and Zuberbühler 2006, 2008), and referential usage is limited to narrow classes of objects, such as major predators or foods. Referentiality appears to be functional rather than intentional (Cheney and Seyfarth 1990; Hauser 1996), and the best interpretation of functionally referential calls remains disputed (e.g. Owren and Rendall 1997). Most striking of all, the vocal repertoire of monkeys and apes is to all intents and purposes fixed. True, the appropriate circumstances in which to call and the class of referent to which a call is given changes with experience (Seyfarth and Cheney 1986), and a caller may learn when to keep silent, when to call and how loudly (Hauser 1992). But call types themselves are species-typical, and the set cannot be augmented. Even home-rearing by humans intent on teaching the words 
of language produces almost no change in the vocal repertoire of the chimpanzee (Hayes 1951; Kellogg and Kellogg 1933). The productive, open characteristic of human language is entirely missing in non-human primate repertoires (Hockett 1960).

Considerable excitement, therefore, has been generated by the discovery that gestural communication in great apes is more flexible and apparently under greater voluntary control. With human help, great apes were shown able to acquire repertoires of tens or hundreds of gestures, which were certainly not species-typical since they were part of American Sign Language (Gardner et al. 1989; Miles 1990; Patterson and Linden 1981). The gestures of 'ape language' subjects were often used in ways that were unambiguously intentional, and no clear limit on repertoire size was noted. The potential for productivity in great ape gesture has been confirmed by finding gestures unique to particular individuals, living in the social circumstances of normal captivity, both in chimpanzees (Tomasello et al. 1985, 1989, 1994) and gorillas (Tanner and Byrne 1996, 1999). Direct comparison between vocal and gestural signalling in the two chimpanzee species has shown that gesture is far more flexible in its usage than vocalization (Pollick and de Waal 2007).

The voluntary, intentional nature of gesture use has been described in all species of great ape. Contrary to the 'one signal, one function' approach so successful in animal communication research, including that on primate vocalizations, a means-ends dissociation between gesture and context was found in chimpanzees, bonobos, gorillas and orangutans (Call and Tomasello 2007c; Liebal 2007; Pika 2007a, b). Many gestures were used in more than one context, and several different gestures were often used within a single context; such flexibility is equally typical of the communication of young children (Bates et al. 1979; Bruner 1972).

Gesturing of great apes is appropriately adjusted to the attentional state of the recipient. Silent, visual gestures are given mainly when recipients are looking; audible, visual gestures less so; and tactile (contact) gestures are given indiscriminately of the audience's attention (Call and Tomasello 2007a, pp. 212-216; Tanner and Byrne 1996). Experimentally, gorillas were found to take a (human) observer's attentional state into account, gesturing more when the observer was present, and when the observer was looking towards them (Poss et al. 2006). One gorilla developed the trick of hiding its 'playface' expression with its hands, which effectively delayed or prevented the onset of play with the partner (Tanner and Byrne 1993). This neatly demonstrates the gorilla's voluntary manual control compared to its involuntary facial expression, and suggests some understanding of vision as an attentional state. When thwarted of its immediate aim, an ape will often sequence several different gestures together (Call and Tomasello 2007a, pp. 209-212). The choice of gesture in such circumstances shows clearly that the ape is able to take account of the degree of understanding of the audience, not simply the presence or identity of individuals (Cartmill and Byrne 2007). When audience reactions show that gestures have been partly understood, the ape persists with the same gestures; when complete incomprehension is evident, the ape switches to a different set of gestures.

Despite flexible intentional usage of an extensive and extensible repertoire, no sign of local 'languages' has been noted in great ape gestural repertoires. If non-human great apes have cultural traditions in their gestural communication, these must be subtle and quite unlike the differences between human languages. This finding leads to an obvious sequel question: if ape gestures are in the main not learnt culturally, how are they acquired? Call and Tomasello (2007a, p. 216) have coordinated studies of gesture in all genera of great apes, with an ultimate hope of gaining hints about the evolution of human language, and the answer they give is unambiguous: 'ontogenetic ritualization, in which individuals essentially shape one another's behaviour'.

The theory of ontogenetic ritualization

Ontogenetic ritualization (OR) is envisaged as progressive transformation of normal, functional behaviour, under the influence of unintentional reinforcement (shaping) by a partner, to become an intentionally used signal (Tomasello 1996). According to the theory, an ape originally uses a physically effective sequence of actions in order to achieve some goal from a partner. Over time, the partner begins to anticipate the whole performance on the basis of some early step in it, and thus responds in the appropriate way, in anticipation. As a result, that early step alone is reinforced and becomes 'ritualized' into a communicative signal. Thus, a physically ineffective action comes to be used communicatively to attain the goal for which the whole performance was originally used (Tomasello and Call 2007, pp. 5-6). Characteristically, actions liable to be ritualized as communication in this way will derive from the starting movements of an action sequence that is capable of attaining the goal by direct physical means, or intention movements typically given before such a sequence.

Since conditioning by reinforcement is held to be the means of acquisition in OR, neither of the communicating partners need to have any insight into the means of operation of the communication. Thus, while an individual might come by OR to use one action intentionally as a signal to influence another, understanding of that signal as meaningful communication cannot be presumed. Therefore, when attempting to communicate the same intention, the partner would not automatically use the same gesture. This is quite different to the case of human language, 
where each individual is a 'speaker-hearer': if I have learnt what you mean by 'zug' I can immediately use 'zug' to you to convey that same meaning.

In principle, any regularly occurring part of the original, physically effective sequence might become ritualized to function communicatively, so that different individuals might learn physically different actions for the same purpose. Thus, the occurrence of idiosyncratic gestures, unique to a single individual within a group, can be readily explained. Such idiosyncratic gesture use has been noted in all studies of great ape gesturing, supporting the theory that ape gestures are acquired by means of OR (Call and Tomasello 2007b). In contrast, no studies have detected the hallmark of cultural acquisition of signals: many gestures used extensively or universally within a single group or local population, but not elsewhere (for cases of single gestures that appear to be acquired culturally, see de Waal and Seres 1997; McGrew and Tutin 1978; Nishida 1980). Admittedly, in most studies one or two gestures have been noted as specific to a single group and not obviously explicable by particular opportunities of the local environment, but when variability among individuals was compared within and between groups it was found to be comparable (Call and Tomasello 2007a, p. 207). Tomasello and Call (2007, p. 10) also distinguish attention getters, gestures with no specific message, in the sense of Smith (1965), which function only to attract attention to the signaller's current mood, as shown by its involuntary facial expression, or to a second (meaningful) gesture. Many great ape gestures are indeed used in combination, but the majority of combinations are repetitions of the same gesture or another of similar meaning; chimpanzees, at least, do not seem to use an attention getter to preface a meaningful gesture (Liebal et al. 2004). This leaves somewhat in limbo the concept of 'attention getters'. If these particular gestures are not in fact used to draw attention to other gestures which themselves carry the meaning, what are they for? However, Call and Tomasello (2007a) discuss them rather little. Instead, they conclude (p. 216), 'the major learning process involved for ape gestures is clearly ontogenetic ritualization'.

\section{Alternative theories of gestural origins}

Two other theories of gestural ontogeny have not been examined in such detail, however. King (2004) proposes that, rather than ritualization by coincidental shaping in dyadic interactions, the manner in which gestures are used as communication is 'mutually constructed' in real time by all parties, in complex and subtle interactions. King contrasts her approach to the traditional one, in which information is seen as transferred via signals, sent in some modality between autonomous agents, the sender and the receiver. Instead of information transfer, for King "movements (of the face, body, limbs, or vocal tract) become communicative when the social partners enter into an interaction. The social partners are anything but autonomous, because they may transform each other as they act" (King 2004, p. 52, her italics). Although this approach is philosophically far from the animal learning theory employed by Tomasello and colleagues as the explanation of gesture ontogeny, it is similar in its reliance on other social individuals as the engine of development (in both cases, explicitly adopting the stance of the influential Russian developmental psychologist, Lev Vygotsky: see Vygotsky 1962). Differences between the two theories in testable predictions may, therefore, be nuanced and hard to detect.

Gestures might also derive from an ape's biological inheritance, as do communicative signals in most other species of animal. Call and Tomasello (2007a, p. 204) do mention that some gestures may be 'species-typical behaviours shaped by evolution not by learning', which they consider would be characterized by 'inflexible use across contexts'. However, they, like all other researchers who have examined ape gesture, find flexible use of gestures to be the norm. Thus, they are inclined to dismiss any pervasive influence of species biology when it comes to ontogeny of the most interesting ape gestures, gestures used in a flexible way to communicate intentions.

\section{Plan of the present study}

We are less confident that it is appropriate to partition meaningful gestures into two mutually exclusive classes: i.e. innate, species-typical signals used inflexibly when elicited by circumstances, versus learned signals, flexibly deployed with careful attention to the audience's attentional state. Humans certainly gesture flexibly, and sometimes with full insight into the means of the gestures' operation as communicative signals, yet many gestures are universal among people (Darwin 1872; Eibl-Eibesfeldt 1972). Equally, there is little doubt that a plover's 'broken wing' display towards potential predators is innate, since it is universal in the family Charadriidae (del Hoyo et al. 1996). Yet piping plovers take account of a predator's direction of gaze (Ristau 1991), and react flexibly to failure. Thus, if the first deployment of the broken wing display fails, the bird will repeat the display where it can better be seen by the predator that is causing concern.

Here, we present a comparative analysis aimed at determining which of the potential theories of ontogeny best accounts for gestural repertoires in a great ape species, concentrating on aspects where theories (in particular, ontogenetic ritualization and biological inheritance) most differ in their predictions. We examined gesturing in the 
Western Gorilla (Gorilla gorilla), the great ape whose repertoire of gestures among captive individuals has been found the largest, both in total and per individual (Call and Tomasello 2007a, p. 198). Several European zoos allowed us to study their gorilla groups, none of which had any contact with each other. In addition, we analysed data from the wild (Mbeli Bai, Republic of Congo), based on a shortterm study specifically of gesture (EG, RWB) and video records of gesturing made ad lib over a longer period (TB). The Western Gorilla has been studied previously by two independent research groups (Pika 2007b; Pika et al. 2003; Tanner 1998; Tanner and Byrne 1999), allowing us to make comparison also with repertoires at further sites.

We began by asking whether those gestures that gorillas use in a meaningful, intentional way are best understood typically as a result of ontogenetic ritualization, as argued by Pika (2007b, p. 121, Call and Tomasello 2007a, p. 216). We collected samples of potential gestural communication using a very broad definition of gesture, mainly excluding cases where the action was sufficient to gain the result by physical force alone. But then, we applied a strict set of criteria for intentional usage, discarding all cases that did not meet the following criteria: (1) gesture was given in such a way that the potential audience could readily perceive it, e.g. silent gestures must be given when others could see them. (2) Gesture appeared targeted at a specific and plausible goal for the signaller, e.g. aimed towards attainment of something the signaller has already shown interest in, at the time of gesturing or in similar previous circumstances. (3) Subsequent behaviour of the signaller was consistent with that goal, e.g. persisting in goal-directed attempts if the result was not obtained, but ceasing to gesture when it was. (Note that there is no theoretical interest in investigating gestures used non-intentionally. It is not in contention that automatic and reflex-like gestures do exist, as part of the biological inheritance of many species including the human.) For any gesture whose deployment met these criteria, we examined whether the gesture's form matched the predictions of the theory of ontogenetic ritualization, i.e. was the gesture similar in form to an early part of the behavioural sequence normally used to achieve the same goal by direct means, or similar to an intention movement given before this behaviour? Then, since ontogenetic ritualization proved an incomplete explanation for intentional gesturing in the gorilla, we went on to ask whether cultural learning also contributed to the ontogeny of gesture repertoires. A cultural tradition would be strongly suspected if a gesture was used by all individuals in one local population but in none at other sites, despite broadly similar social compositions and local living conditions. Where some gestures might be explained as originating in ontogenetic ritualization but others could not, we asked whether these two classes of gesture differed systematically. For instance, a different ontogeny might be reflected in: (1) degree of intentionality, such as whether attention is paid to the potential audience's attentional state. (2) Flexibility, such as the means/ends dissociation noted by Call and Tomasello to be characteristic of flexible, intentional gesturing by great apes. (3) Range of meanings, such as the fixity or otherwise of meaning across different local populations. Finally, rather than this 'multiple-origins' approach, we asked whether any other single-origin hypothesis might account better for the observed patterns of usage.

\section{Methods}

\section{Subjects}

Captive groups of Western Gorillas (Gorilla gorilla gorilla) were observed in three European zoos (Basel and Zurich, Switzerland and La Vallée des Singes, France), and wild gorillas were studied at Mbeli Bai, Nouabalé-Ndoki National Park, Republic of Congo. We treated individuals up to 3 years old as infants, those above 3 years but less than 6 years old as juveniles, and those of at least 6 years but less than 10 years old as adolescents. For the wild gorillas at Mbeli Bai, we used age categories after Breuer et al. (2009).

The gorilla group at La Vallée des Singes consisted of ten individuals at the time of observation: 1 silverback (24 years old), 3 adult females (24, 36 and 36 years old), 2 adolescents ( 6 and 8 years old males), 1 juvenile (a female of 5 years), and 3 infants ( 2 males of 2.5 years and 1 female of 15 months). The group at Basel Zoo comprised 11 individuals: 1 silverback (18 years old), 5 adult females (48, 46, 39, 18 and 16 years old), 3 adolescents ( 2 males of 7 and 8 years and 1 female of 7 years), 1 juvenile (5 years old male), and 1 infant (1 year old female). In addition, we analysed archival film of one adult female, Achilla, wild born in 1947 and thus 26 years old at the time of filming; she died in 1987. The group at Zurich Zoo comprised 9 gorillas: 1 silverback (31 years old), 2 adult females (31 and 27 years old), 4 adolescents ( 3 males of 7-8 years old and 1 female of 7 years) and 2 infants ( 1 male, 1 female, both 3 years old). At Mbeli Bai, gorilla groups in the local population totalled ca. 130 individuals, including single males, harems and breeding groups (see Parnell 2002 and Breuer et al. 2009 for full details of the population).

\section{Environment}

The three zoo-based groups inhabited relatively similar environments, designed to allow enrichment and encourage behaviour as natural as possible within captive conditions, and differing mainly in details. Those gorillas observed at La Vallée des Singes were in an enclosure 
composed of an indoor facility $\left(125 \mathrm{~m}^{2}\right)$ provided with ropes, suspended tyres and several separate compartments. Window-walls on one side allowed visitors to observe the gorillas when kept inside. The outdoor enclosure was a wooded island $\left(3,800 \mathrm{~m}^{2}\right)$, surrounded by a stream that provided natural separation between gorillas and visitors. The gorillas spent from around 0930 hours until 1700 hours outside. They were fed six times a day with various fruits, vegetables, nuts, cereals and tree cuttings, with water available ad lib. Basel Zoo gorillas lived in an entirely indoor enclosure divided in three parts $\left(100 \mathrm{~m}^{2}\right)$ and provided with ropes, fake trees, and swings. Additionally, other objects such as buckets and paper were provided every day for enrichment. The gorillas were fed every hour with various fruits, vegetables, nuts, cereals, seeds, tree cuttings, eggs, fruit juice, and monkey cakes; water was available ad lib. Zurich Zoo gorillas had an indoor enclosure provided with ropes and tree trunks $\left(108+20 \mathrm{~m}^{2}\right.$ backstage), and when weather allowed they also had access for several hours a day to an outdoor enclosure $\left(110 \mathrm{~m}^{2}\right)$. They were fed every hour with various fruits, vegetables, seeds, and tree cuttings; water was available ad lib.

The habitat in which the wild gorilla population of Mbeli Bai, Congo, was observed consists of a 13 ha open area of pools and semi-stable floating vegetation surrounded by forest. Gorillas and other mammals visit this "bai" to pull out and eat vegetation from the water. Several gorilla groups and solitary males visit the bai, separately and sometimes together, and are observed at ranges from 10 to $0.4 \mathrm{~km}$ from an $8 \mathrm{~m}$ high observation platform. All individuals seem habituated to observation from this tower, but have not been followed into the forest in which they spend most of their lives.

\section{Procedure and analysis}

Captive gorillas were observed on an average $6 \mathrm{~h}$ a day (5$7 \mathrm{~h}$ ); daily observation time for wild gorillas was determined by their visits to the bai, within a typical-day of $9 \mathrm{~h}$ watching from the tower. We observed gorillas at $\mathrm{La}$ Vallée, Basel and Zurich for 25 days at each site, which resulted in $125-175 \mathrm{~h}$ observation time per site. We recorded potentially communicative events on miniDV with a Sony Handycam (DCR-HC 24). E.G. and R.W.B. observed Mbeli Bai gorillas for a 7 week intensive period, which resulted in $240 \mathrm{~h}$ gorilla observation time; however, during only a small fraction of this time did any gorilla engage in social activity (less than $1 \mathrm{~min}$ per hour of film). In addition, we analysed video material, including gorilla gestural communication, collected ad lib over a 3-yearperiod by $\mathrm{TB}$, for events that were potentially communicative.
To obtain video records, we focused attention on "potentially communicative" episodes, i.e. those involving at least two individuals, in which interaction was apparently sought or initiated by one individual. The aim was to make a broad trawl, and the boundaries of behaviour that was selected as potentially communicative are therefore vague. Indeed, much of the filmed material did not prove to involve use of gestural communication. In addition, episodes of solitary play were recorded.

Video records were then examined for the occurrence of potential gestural communication, and for each case a clip was made with I-Movie and indexed for analysis with Filemaker Pro. Potential gestures were identified on deliberately broad criteria, but attention was restricted to non-mechanically effective acts, including body postures, body movements and movements of the limbs and head. In addition, the actions of the gorilla must have been potentially detectable by an audience, if there was one (e.g. visible movements, audible results of movements, or tactile pressure from body contact), and the actions should not serve to attain the presumed goal by direct, nоn-соттиnicative means. This last criterion was straightforward to apply to non-contact actions, but ambiguity often remained in the case of putative tactile gestures, where it is hard for an observer to estimate the degree of force applied. Each potential gesture was coded for the situational context, sensory modality (visible/silent, visible/audible, tactile), and identity of signaller. We recorded any potential audience, whether the gesture appeared directed at a particular recipient, and if it did we noted the attentional state of that recipient and any response they gave to the gesture, as well as the outcome of the interaction. Two of the authors, E.G. and C.H., coded the tapes independently, and repeatedly compared their coding to ensure high agreement.

These potential gestures were then filtered, by removing any instances that did not meet strict criteria for the intentional nature of their use. We consider a gesture to be, necessarily, an intentionally communicative act. However, in practice, clear indicators of the intention behind them may not accompany many or most uses of gestures. The position is further complicated by the possibility that individuals may sometimes choose to use gestures outside communicative contexts (e.g. in solitary play). Filtering out cases that did not include evidence of intentional use is therefore highly conservative: no doubt many genuine cases of gesture use were thereby removed.

To be considered intentional, a gesture must be given by an individual in a goal-directed way. There must be some plausibly desired result to be obtained, and when this result is not gained immediately then response waiting is expected (Tomasello and Call 2007; Tomasello et al. 1994), followed by persistence and elaboration in signalling, such as repeating the same gesture or using others 
(Cartmill and Byrne 2007; Leavens et al. 2005). These criteria may appear harsh, but since in our study, as in most previous work, the majority of gestures were observed in the context of juvenile play, plausible playful goals were in fact relatively easy to imagine. More restrictive was the additional criterion that the gesture must be directed at an appropriate audience. What this means must necessarily vary with the modality of the gesture. Tactile gestures, by definition, involve contact with another individual, to whom the gesture is considered to be directed. Silent, visual gestures must be given when an appropriate audience is potentially able to see them, and the signaller must be oriented towards and looking at that individual or those individuals, either just before or at the time of the gesturing. Of course, humans are capable of giving a gesture for a target audience without ever making them a focus of vision: for instance, in deliberately surreptitious signalling. We accept the possibility that our approach will occasionally miss the real target of a gesture, but there seems little alternative to this sort of simplifying assumption. Audible gestures present the greatest problem for determining the intended target, since by their nature they are appropriate for use without determining whether the target audience is attending. In this case, we required only that the signaller should be oriented towards and looking at the presumed target individual, and that their subsequent behaviour should be consistent with that assignment, i.e. if the target fails to orient towards the signaller, persistence with audible gestures or switching to the tactile modality is expected.

In addition, we restricted most analyses to gestures occurring singly. Where gestures were given in sequences, i.e. strings of gestures with no pause greater than $1 \mathrm{~s}$, we used only the first gesture in the sequence to reduce problems of non-independence. Gestures used in the middle of rough-and-tumble play were also excluded, because of the difficulty of discerning their target audience and goal in the melee of close interaction. However, gestures initiating play sequences were included.

The resulting set of intentional gestures was then used to work out the (minimal) repertoires of individuals, and each gesture's approximate meaning as used by that individual. We examined patterns of gesture occurrence within and between social groups, in particular measuring the extent of idiosyncrasy and commonality within communities (since our procedure is conservative, and must inevitably underestimate repertoires, we also computed the distribution of the full set of 'potential gestures' to avoid falsely attributing absence to individuals and social groups.), we charted the flexibility or rigidity of use of gestures, and whether signallers paid any attention to the attentional state of their audiences. Where some gestures could reasonably have been learnt by ontogenetic ritualization, whereas others could not, we examined these variables for both sets of gestures independently.

\section{Results}

We recorded $105 \mathrm{~h}$ of gorilla behaviour that had the potential to show gestural communication, in which 9,540 potential gestures were identified. Once our strict criteria for intentional usage were applied, the number of instances of gesture fell to 5,254 cases. In each of these, the gesture was definitely made in an intentional way; note, however, that some of the cases set aside may reflect communicative gestures that happened not to give evidence of their intentional use during our observations. This procedure resulted in a repertoire of 102 different gestures (see "Appendix"). Juvenile and adolescent animals (3-10 years) were responsible for using the highest number of gesture types (see Fig. 1), compared to a smaller variety used by infants ( $<3$ years $)$, or adults of either sex.

\section{Repertoire overlap between individuals and groups}

We compared the degree of sharing of repertoires between individuals of the same age class, both within and between social groups, using Cohen's kappa as a measure of concordance. Within groups, concordance was quite variable: La Vallée, adult females 0.45, juveniles 0.54; Basel, adult females 0.41, juveniles 0.53; Zurich, adult females 0.03, juveniles 0.58 . The lower values for adults are presumably a consequence of underestimating repertoires, since adult gorillas gestured much less frequently than juveniles. Differences between groups in kappa values were not significant (Kruskal Wallis ANOVA on adult females, $N=10$, $\chi^{2}=2.47, \quad d f=2, \quad P=0.29 ; \quad$ on juveniles, $\quad N=31$, $\left.\chi^{2}=3.70, d f=2, P=0.16\right)$, although considerations of statistical power and independence of inter-individual scores

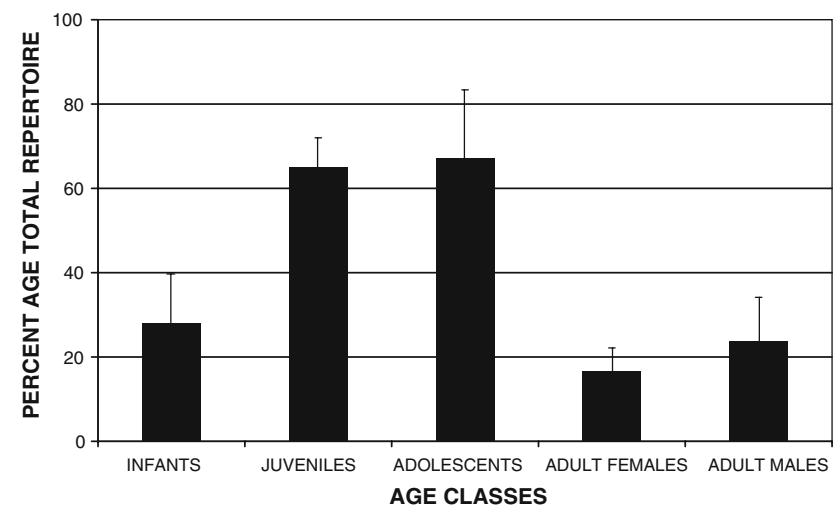

Fig. 1 Age distribution of gorilla gesture. The percentage of the total gorilla repertoire used by each age class. Error bars represent standard deviation across sites 
make firm conclusions difficult. Concordance in repertoires between groups appeared broadly similar to that found within groups: adult females, 0.30 , juveniles 0.54 . (In this case, pooling data from all three captive groups gave sufficient data also to estimate values for infants, 0.28 and for adult males, 0.42). However, statistical comparison revealed that values were in fact significantly different: kappa values are significantly smaller between groups than within groups (Mann-Whitney test on adult females, $N_{1}=10, N_{2}=26$, $U=74, Z=-1.98, P=0.047$; on juveniles, $N_{1}=31$, $\left.N_{2}=83, U=724, Z=-3.58, P<0.001\right)$.

The great majority of intentional gestures $(85 \%)$ were found at more than one of the four sites we worked at, and many (39\%) were recorded at all of them. The remaining $15 \%$ were found at only one site. In that case, absence might be due to local environmental conditions, or simply rarity of use causing a gesture to be missed in our sampling. The former was certainly true in some cases. Thus, at sites where gorillas were not provided with detached objects that could be easily manipulated, gestures involving objects were missing (e.g. throw threat, rope spinning, push object, shake object, throw object, head shake with object, knock object). In several other cases, although a gesture was missing from the corpus of intentional gesturing at a site, it was noted as used on occasions when we could not be sure of intentional use, including use within sequences of other gestures. In this case, apparent absence in the main corpus could readily be explained as a sampling effect (e.g. stomp, stomp object, multiple stomp, arm shake). Finally, to test whether in general a gesture's frequency of use did indeed affect the chance of it being detected during our sampling periods; we correlated the total recorded number of instances of a gesture with the number of sites at which we noted it. The correlation was positive (Pearson's $r=0.43, P \leq 0.001, N=84$, excluding cases explained satisfactorily by local environmental variations; see Fig. 2). We therefore conclude that apparently patchy distributions across sites are generally an artefact of sampling or local environmental affordances, and the great majority of gorilla gestures are universal.

Evidence of cultural traditions and idiosyncrasy

Seventeen gestures were recorded as used intentionally at only one site. Since absences from certain sites are likely to be a function of environmental and sampling effects, the possibility exists that 'idiosyncratic' or 'group specific' gestures might be falsely identified, artefacts of insufficient sampling. For a species with a large gestural repertoire, such as the Western Gorilla, the repertoire recorded for an individual is liable to increase over a long period of observation (e.g. new gestures were still being found at the end of an 11 years study: Tanner and Byrne 1999). Our

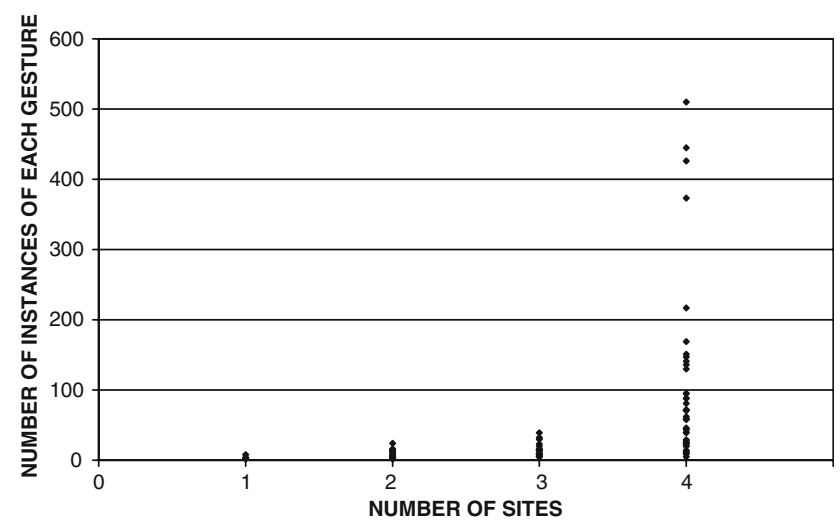

Fig. 2 Distribution as a function of usage frequency. The total number of observed instances of a gesture in (intentional) use, plotted according to the number of independent sites at which it was recorded

sampling was necessarily carried out over much shorter periods, and is thus unlikely to be sufficient to pick up the rarest gestures for all individuals. To avoid false diagnosis of any idiosyncratic or group specific gestures, we examined all instances of possible gesture use for occurrence of any of these 17 gesture types, i.e. including cases lacking positive evidence of intentionality and instances given in sequences of gesturing.

Using this procedure, we identified only eight gestures that were each recorded solely within one local population (Table 1). Of these, one was idiosyncratic, i.e. unique to a single gorilla at La Vallée, and that was a gesture performed only to a keeper not to other gorillas. Seven gestures were group specific, i.e. each was used by more than one individual at the only site where it was observed. However, the group specific nature of two of these may readily be explained by environmental affordances. 1-Handed move object was only found at Basel, where access was given to detached objects too big and awkward to carry but nevertheless moveable and water splash was only found at Mbeli Bai, where the place the gorillas were observed included large areas of shallow water. The lack of similar opportunities at the other sites might explain the absence of these gestures at them. Thus, we would point to only five gestures as showing a possible cultural ontogeny. One of these, bite wrist + arm shake, was performed by only one individual at Basel during our study, but was also noted in a film of the Basel Zoo gorillas in 1973, made and kindly loaned to us by Dr. Jorg Hess, "Prerequisites of highly organized behaviour of gorillas in captivity". At that time, the gesture was given by a now-dead individual, Achilla, the great-grandmother of Viatu, the gorilla who performed the gesture in the current study. Thus, vertical cultural transmission of gesture form might have occurred, although we cannot discount the possibility that this coincidence was a result of some genetic oddity that both 
females shared by inheritance. In addition, the possibility of independent invention by the two gorillas cannot be discounted, although the gesture is an odd one so this would be highly coincidental. The fact that all these five possible cases of possible cultural tradition occurred at Basel Zoo is intriguing, and we can only suggest that the extensive artificial enrichment opportunities for gorillas given at this zoo may have increased the opportunities for such traditions to develop.

Procedure for examining hypothesis of ontogenetic ritualization

Subsequent analyses were restricted to gestures recorded as used intentionally at all four sites (see Table 2). We examined the form of each gesture, in relation to its apparent goal, in order to determine whether the gesture resembled in any way an action that could bring about that goal directly, or an intention movement that might be expected to precede such action. For example, the gesture slap other has the apparent function of initiating contact play, and could have become ritualized from a physically effective slapping action sufficient to achieve the same aim. Conversely, pirouette (moving forward while twirling the body about the vertical axis), which in our studies appears to function in terminating play, does not seem in any way related to physically effective ways of achieving that aim.

Those gestures, for which an origin in ontogenetic ritualization is plausible, appear to be derived from several different activities. Many appear ritualized from acts used in play, including chasing, wrestling and other contact play activities, into play start signals or an attention getters (1-handed grab, 2-handed grab, 2-handed grab-pull, grabpull, bite, pounce, punch, push 1-handed, push 2-handed, slap other, slap other 2-handed, touch, embrace, hit with object, kick; see "Appendix" for definitions of gestures).
Others appear to have originated in grooming (stroking, poke), agonism (arm raise, arms raise, from attempted slapping), balance control (arm swing, arm swing with object, from actions useful during running), or physically manipulating others (arm swing under, positioning, from bodily moving another; arms wave, reach, from attempt to grab another; hand on, hands on, from acting to prevent another's movement; leg swing, from kicking), carrying or manipulating objects (object on head, rope spinning, throw threat, now apparently play start signals).

Some gestures, however, could not be explained as derived from physically effective means of achieving their goal, with any degree of plausibility. In most cases, these gestures instead resembled parts of species-typical displays of the Western Gorilla, such as chest beating or foot stomping (for example, tapping object, clap, body beat, pirouette, stiff walk). Provisionally, we termed these gestures 'species-typical', to contrast with those which might result from ontogenetic ritualization of intention movements or physically effective actions, which we termed 'potentially ritualized' (Table 2 reflects this categorization).

\section{Flexibility of usage}

Following the approach of Call and Tomasello (2007a, b, c), we estimated the flexibility of use of each gesture by recording the range of situational contexts in which it was used (i.e. playing, agonism, feeding, nursing, affiliation, sexual, travel). Ideally, we would have used individuals as the data points in these analyses to ensure independence; however, this would have resulted in too few data to analyse statistically, so we-like previous researchers-were obliged to use gestures as the unit of analysis. Both potentially ritualized and species-typical gestures were found in several contexts, although the spread was significantly greater for potentially ritualized gestures, which
Table 1 Gestures restricted to single sites

\begin{tabular}{|c|c|c|c|c|c|c|c|c|}
\hline & \multicolumn{4}{|c|}{ Number of instances } & \multicolumn{4}{|c|}{ Number of individuals } \\
\hline & Basel & La Vallée & Zurich & Mbeli & Basel & La Vallée & Zurich & Mbeli \\
\hline \multicolumn{9}{|l|}{ Group specific gestures } \\
\hline One-handed move object & 31 & & & & 4 & & & \\
\hline Water splash & & & & 3 & & & & 3 \\
\hline Lick hand & 64 & & & & 3 & & & \\
\hline Bite + arms shake on & 39 & & & & 4 & & & \\
\hline Arm swing under with object & 37 & & & & 4 & & & \\
\hline Arms swing with object & 11 & & & & 3 & & & \\
\hline Bite wrist + arm shake & 9 & & & & 2 & & & \\
\hline \multicolumn{9}{|l|}{ Idiosyncratic gestures } \\
\hline Disco arms shake & & 8 & & & & 1 & & \\
\hline
\end{tabular}




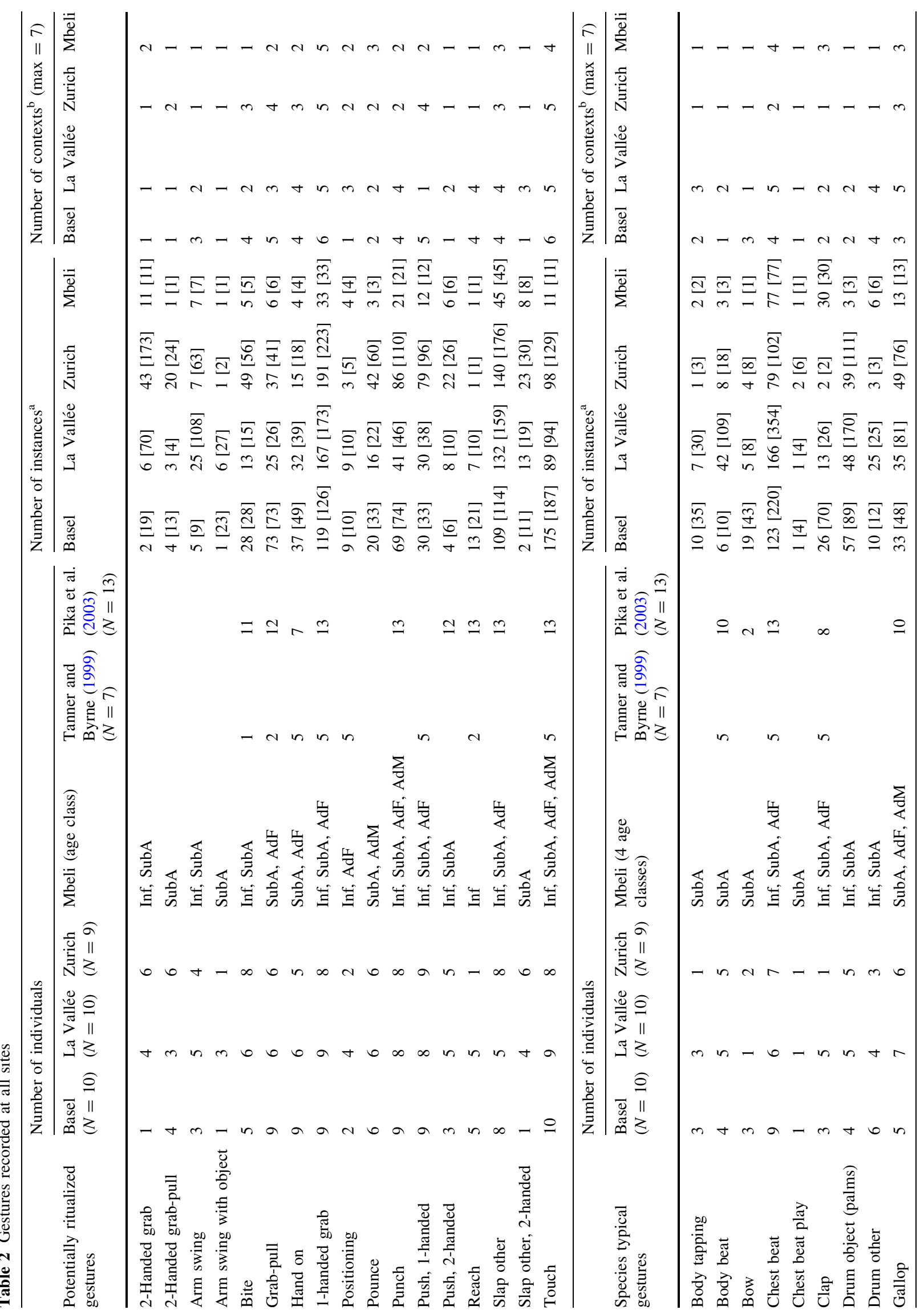




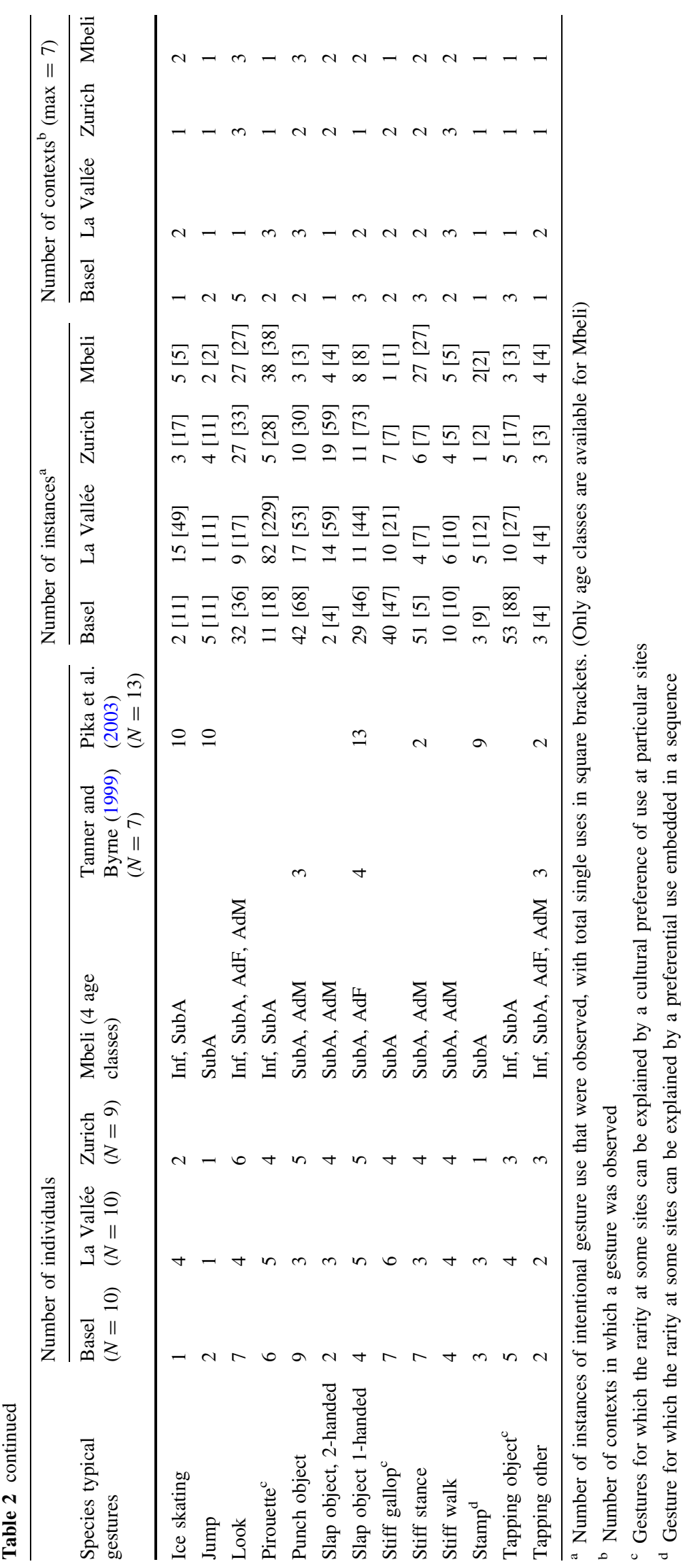




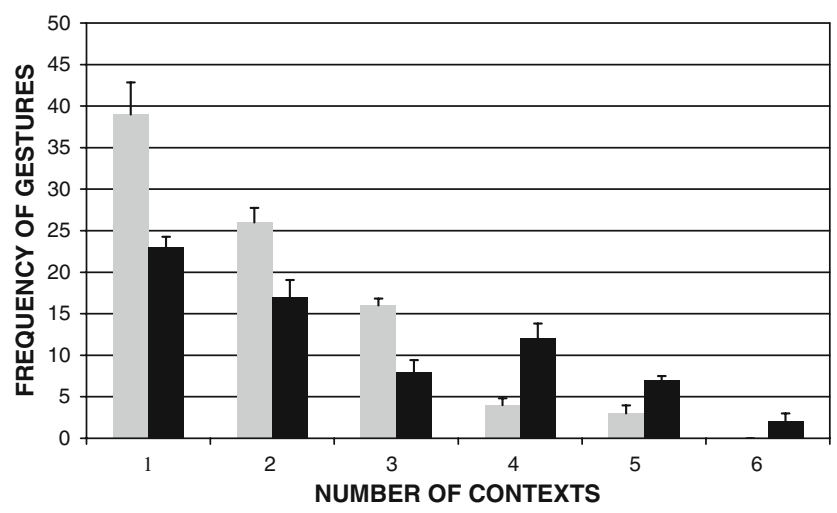

Fig. 3 Gestural flexibility. The frequency of gestures is plotted according to the number of contexts in which they are used. Grey bars represent species-typical gestures, black bars potentially ritualized gestures. Error bars represent standard deviation across sites

were found in up to six contexts rather than five for species-typical gestures (Fig. $3 ; \chi^{2}=14.2, d f=5, P \leq 0.05$ ). To examine this association in more detail, we compared the frequencies with which specific contexts elicited the use of potentially ritualized or species-typical gestures. Gestures which may have derived from ontogenetic ritualization were found in a significantly wider range of contexts $\left(\chi^{2}=126.6, d f=6, P \leq 0.05\right.$; note that Fig. 4 shows percentage values), as predicted by the ontogenetic ritualization hypothesis. However, note that in both these cases the differences are small and overlap in usage pattern is the norm. In most contexts, a range of gestures of either type was used, and only for nursing and travel were gestures exclusively ones that might have derived from ontogenetic ritualization. Thus, while we found statistically significant differences, it is difficult to imagine they have psychological significance.

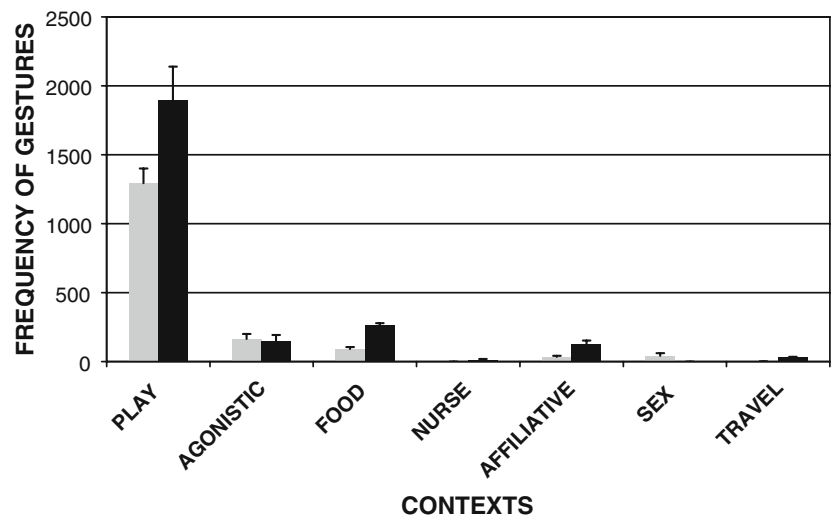

Fig. 4 Context specificity of gestures. The frequency of gestures is plotted for each of the situational contexts in which they are used. Grey bars represent species-typical gestures, black bars potentially ritualized ones. Error bars represent standard deviation across sites
Variations in gesture function

Although repertoires of gorilla gestures were similar, if not identical, across groups as well as individuals, it might be that this uniformity was restricted to gesture form. Because gestures are used in very flexible ways, perhaps gestures acquire their meanings by individual learning and thus the true extent of idiosyncrasy across individuals or local traditions will be revealed only if gesture function is examined.

To test this assumption, we selected five potentially ritualized and five species-typical gestures which had the highest frequency of use across all three captive sites, as well as showing frequent use in the wild. For all these ten gestures, at least three individuals and in most cases more employed the gesture in each of the three captive groups. This allowed us to analyse their meaning, in the sense of the instrumental function, comparing between individuals in each group and between groups. To assess the function of each gesture for each individual, we catalogued the behavioural reactions of the recipient each time the gesture was used, excluding gesture sequences from analysis. We used the conditions that apparently elicited the gesture, and the reactions that the gesturing gorilla apparently sought from using the gesture, to indicate likely functions, and were able to distinguish ten distinct categories. These were "Approach invitation": elicits the approach of a recipient, often followed by start of play. "Attention getter": causes a recipient to stop current activity and turn around to look at signaller, in which case signaller gestures again. "Calm down request": causes an excited recipient to calm its activity. "Chase invitation": elicits playful chasing by recipient, either recipient starts chasing signaller or starts running away to be chased. "Contact play invitation": causes recipient to approach and make body contact to start playing, usually rough-and-tumble or wrestling play. "Cuddle invitation": causes recipient to approach, to cuddle or to be cuddled. "Displace": causes recipient to change its location or position. "Stop": request for recipient to stop current activity. "Stop approach": causes recipient to stop progressing towards or passing the signaller; usually recipient sits down or marks a pause. "Travel invitation": elicits travel, e.g. mother's request to infant to start moving, infant's request to mother to ride. For all cases where sufficient evidence of the function of gesturing was available, we assigned one of these ten categories (see Table 3, in which the first five gestures, throw object to touch, are potentially ritualized, and the remainder are species-typical).

Inter-observer reliability was examined by asking an independent observer to rate $50 \mathrm{clips}$, spanning all gestures and individuals, for whether any of the ten functions was appropriate or not; overall level of agreement was high, 
Table 3 Instrumental functions of gestures

\begin{tabular}{|c|c|c|c|c|c|c|c|c|c|c|c|}
\hline Function $^{1}$ & $\begin{array}{l}\text { Throw } \\
\text { object } * *\end{array}$ & Hand on $* *$ & $\begin{array}{l}\text { One-handed } \\
\text { grab } * *\end{array}$ & $\begin{array}{l}\text { Slap } \\
\text { other } * *\end{array}$ & Touch $* *$ & $\begin{array}{l}\text { Chest } \\
\text { beat* }\end{array}$ & $\begin{array}{l}\text { Drum } \\
\text { object } * *\end{array}$ & Gallop ** & Pirouette $* *$ & $\begin{array}{l}\text { Punch } \\
\text { object }\end{array}$ & Total \\
\hline Approach invitation & 3 & 0 & 0 & 0 & 1 & 1 & 6 & 0 & 0 & 0 & 11 \\
\hline Attention getter & 3 & 0 & 6 & 8 & 32 & 0 & 4 & 1 & 0 & 2 & 56 \\
\hline Calm down request & 0 & 32 & 25 & 11 & 29 & 1 & 0 & 1 & 0 & 0 & 99 \\
\hline Chase invitation & 16 & 0 & 3 & 26 & 7 & 8 & 19 & 21 & 21 & 5 & 126 \\
\hline Contact play invitation & 6 & 7 & 111 & 49 & 39 & 28 & 18 & 10 & 11 & 7 & 286 \\
\hline Cuddle invitation & 0 & 12 & 8 & 5 & 25 & 1 & 1 & 0 & 0 & 0 & 52 \\
\hline Displace & 24 & 3 & 61 & 60 & 33 & 21 & 15 & 27 & 0 & 13 & 257 \\
\hline Stop & 5 & 13 & 4 & 39 & 13 & 3 & 0 & 0 & 32 & 0 & 109 \\
\hline Stop approach & 2 & 6 & 16 & 0 & 3 & 0 & 0 & 0 & 0 & 2 & 29 \\
\hline Travel invitation & 0 & 0 & 12 & 0 & 2 & 0 & 0 & 0 & 0 & 0 & 14 \\
\hline Total & 59 & 73 & 246 & 198 & 184 & 63 & 63 & 60 & 64 & 29 & 1039 \\
\hline
\end{tabular}

For definitions of functions, see "Variations in gesture function" in Results section. Numbers represent the frequency of instances in which a gesture was used with each function; the criteria for identifying function were based on recipient reactions, so only cases where a clear effect could be discerned were used in this analysis. Bold type is used for the function of a gesture that was most common overall, with italic for the second most common function

The notation *, ** shows deviation from the overall distribution of assigned functions, i.e. from the distribution shown under "Total", by the level of significance in a goodness of fit $\chi^{2}$ test (respectively: $<0.05,<0.01$ )

Table 4 Cross-site similarity in meaning

\begin{tabular}{llcl}
\hline Gesture type & $\begin{array}{l}\text { Number of } \\
\text { functions }\end{array}$ & $\begin{array}{l}\text { Total } \\
\text { frequency }\end{array}$ & $\begin{array}{l}\text { Major function } \\
\text { same in }\end{array}$ \\
\hline Throw object & 7 & 59 & La Vallée, Zurich \\
Hand on & 6 & 73 & All three groups \\
One-handed grab & 9 & 246 & All three groups \\
Slap other & 7 & 198 & 2 groups \\
Touch & 10 & 184 & Basel, Zurich \\
Chest beat & 6 & 63 & Basel, La Vallée \\
Drum object & 5 & 63 & La Vallée, Zurich \\
Gallop & 4 & 60 & Basel, Zurich \\
Pirouette & 3 & 64 & All three groups \\
Punch object & 4 & 29 & Different in each \\
\hline
\end{tabular}

with a Cohen's kappa value of 0.89. Note that the speciestypical category is by no means dominated by attention getters, although we found that attracting attention was a minor function for several gestures.

We first asked whether the pattern of inferred function genuinely differs among gestures, pooling data across all three social groups. Summing the totals of inferred function over all gestures provided a null hypothesis, against which the distribution of functions for actual gesture could be compared with $\chi^{2}$ as a goodness of fit tests. The results are shown in Table 3: in only one case was the distribution not significantly distinct, and that was the gesture for which least data were available, punch object. Gestures are used in such a way as to produce reliably different effects, which are somewhat consistent across sites.
As is evident from Table 3, however, no gesture has a single, simple meaning: gorilla gestures tend to be multipurpose. Inspection of the assignments for each individual showed that this was true also for any one individual. On an average, we found that gorillas at each zoo use one of these gestures for $4.5 \pm 1.7$ functions, having examined an average of $34.6 \pm 27.5$ instances at each zoo. If these data are split according to possible ontogeny, the numbers remain comparable: potentially ritualized, $5.5 \pm 1.7$ functions per individual per zoo, with $50.7 \pm 28.9$ instances per zoo examined; species-typical, $3.6 \pm 1.1$ functions per individual per zoo, with a much smaller number of instances to examine per zoo, $18.6 \pm 13.3$.

The precise balance of usage will inevitably depend on local circumstances, including social group composition and affordances of the enclosure, even if a gesture's meaning is identical in all groups. To examine the extent to which meaning is shared across groups, therefore, we looked at the commonest assignment in each of the three social groups, for each gesture: how often was that assignment the same in two or three of the groups, and how often was it unique (Table 4). As the table shows, meanings, in the sense of instrumental functions for which gestures are used, are extensively shared between socially isolated groups. Even in the cases where a gesture was used mainly for the identical function at only two out of three facilities, at the third it was also used for that function, merely less often. The only case where the function seemed more variable was once again punch object, the gesture for which we had least response data, less than half the number of cases of any other gesture. The functions of a gesture 
were thus found to be very similar, not only between individuals of the same group but also between groups; this conclusion applied equally to potentially ritualized and to species-typical gestures.

\section{Attention to target's attentional state}

All the cases of gestural communication that we subjected to detailed analysis were pre-selected as showing intentional use, but we made no stipulation that the potential recipient should actually be attending. It was therefore of interest to see whether signallers fine-tuned their choice of gesture, matching the modality of the gesture with the communicative problem, and whether they paid specific attention to the attentional focus of the recipient.

For each gesture, we examined the recipient's attention towards the signaller. Since it is often not possible to be sure of the eye-gaze of gorillas, and gaze generally follows head orientation, we scored as "attending" individuals whose head was facing in the direction of the recipient, $\pm 45^{\circ}$ (see Fig. 5). For both silent-visible and tactile gestures, we found no difference in sensitivity to the audience according to whether the gesture had been categorised as potentially ritualized or species-typical (silent visual $\chi^{2}=3.69, N=1,224, d f=1, P>0.055$; tactile $\chi^{2}=$ $0.15, N=2,112, d f=1, P=0.70$ ).

Because no significant differences were found, we collapsed potentially ritualized and species-typical gestures to examine the possibility of an association between gesture modality and audience attention. In this case, the association was significant: silent, visual gestures were used more often when the recipient was attending, compared to tactile gestures $\left(\chi^{2}=106.0, \quad N=3,336, \quad d f=1, \quad P<0.001\right)$. Audible gestures were all found to be of the species-typical type, and may include some attention getter actions: in no case could a plausible origin for an audible gesture be envisaged from ontogenetic ritualization. Examining only species-typical gestures, we found an association between modality and audience attention $\left(\chi^{2}=13.6, N=1,951\right.$, $d f=2, P<0.01)$, with audible gestures at least as closely associated with recipients attending the signaller as silent, visual gestures.

\section{Discussion}

According to the dominant theory for the origin of gestural communication in great apes (Call and Tomasello 2007a, p. 216), the repertoire of an ape can be divided into two parts. Species-typical gestures can be recognized because they are used inflexibly, in a single or very limited range of behavioural contexts or simply to attract attention. But the largest number of great ape gestures, those of most interest

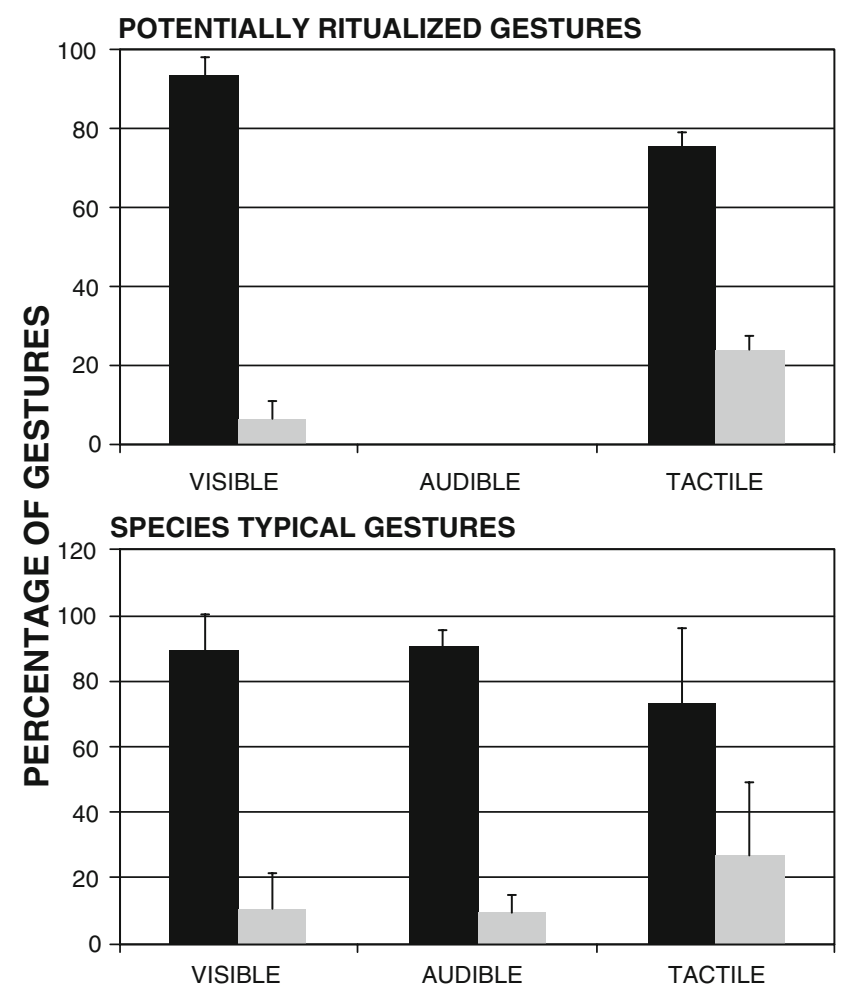

Fig. 5 Sensitivity to audience. The percentage of gestures used as a function of the attentional state of the recipient for each sensory modality (visible, audible and tactile). Separate analyses are performed for potentially ritualized gestures (top) and species-typical gestures (bottom). Black bars represent attending, grey bars represent not attending Error bars represent standard deviation across sites

to the theory of animal communication, are non-speciestypical gestures, used flexibly and intentionally to convey meanings. Such gestures, Tomasello and his collaborators have argued, are acquired by ontogenetic ritualization.

We questioned the aptness of this two-part division, for understanding the origins of the gorilla gestural repertoire. Since there is no doubt that all primate species give some gestural responses in an automatic and unintentional way, cases were only relevant where we could be sure that a gesture was made intentionally. We therefore used a strict criterion of intentionality of use, based on accepted characteristics: direction at a target individual able to perceive the gesture, response waiting, and/or appropriate reactions to a failure to achieve the apparent goal. This greatly reduced the corpus of data, and no doubt some intentionally communicative gestures were thereby missed simply because of their rarity. Nevertheless, we identified 102 gesture types, broadly overlapping with those described in previous studies: the "Appendix" shows mappings to gestures identified in the two previous studies (Pika 2007b; Tanner 1998). The fact that we distinguished a higher number of gestures may have no great significance. Tanner described only 30 gestures among the San Francisco Zoo 
gorillas in an 11-year-study, but she clearly analysed at a somewhat higher 'splitting level' (e.g. our arm shake, arms shake, hand shake, hands shake would all be coded as 'armshake'). In any case, her analysis was restricted to discrete actions of the hands, arms and head, and she worked with only one social group, so a lower number of gesture types is to be expected. Pika (2007b) described 33 distinct gestures at two zoos, Howletts in the UK and Apenheul in the Netherlands; she only studied 13 individuals between 1 year 3 month and 6 years 2 months old, so a smaller repertoire is again to be expected. And as with Tanner's study, Pika's classification was less fine-grained than our own.

To gain an overview of the usage of intentional gesturing, we compared the pattern across individuals, from idiosyncratic use by only one individual at one site through to universal occurrence among individuals at every site. As with previous studies, we found very few gestures suggesting cultural acquisition, i.e. used commonly by several individuals at one site but entirely absent at other sites, without any apparent environmental explanation; we identified five such cases. Intriguingly, one of these was a gesture 'idiosyncratic' to single individuals at the same site in 1973 and 2006, suggesting vertical transfer of knowledge. Tanner (1998) describes three gesture types used by more than one individual in San Francisco Zoo that were not found in our study. However, she noted that all of these gestures had been seen elsewhere: 'chest knock' was also used by the language-trained gorillas Koko and Michael; 'extended palm' had been observed in several zoos and was also described in the wild mountain gorilla (Schaller 1963); 'pat off' had been noted in other zoos, under the term 'patting' or 'swiping'. Pika (2007b) describes two gestures as apparently cultural traditions at Apenheul Zoo, 'arm shake' (performed by six out of seven individuals) and 'chuck up' (performed by 3 out of 7). However, the definition of 'arm shake' resembles Tanner's 'armshake', and a combination of our arm shake, arms shake, hand shake and hands shake, gestures we noted at several sites. Similarly, 'chuck up' resembles our arms raise, which we noted performed by at least three individuals in the wild at Mbeli Bai, and also among gestures seen at La Vallée and Zurich but without evidence of intention. The lack of any general cultural influence on the ontogeny of gorilla gesture was also evident when we examined concordance of repertoires. Although the level of inter-individual concordance was higher within groups than between them, the difference was small and readily explained as a consequence of social and environmental differences in living conditions. It is possible that more general between-group variation might be detected at a finer level of analysis than we used, but since on the whole the categorizations in our ethogram were more fine-grained than those used in other studies that risk is smaller here than in previous work.

Idiosyncratic gesture use was even scarcer, with only one clear instance, and that given to a keeper rather than to other gorillas. This finding is in apparent contrast to previous studies: Tanner (1998) described 13 gestures unique to single individuals at San Francisco Zoo alone; Pika (2007b) noted three gestures idiosyncratic to single individuals at Apenheul. This difference may, however, be illusory. Tanner did not restrict attention to cases where she had evidence of intention to communicate, and included in her glossary gestures made only in solitary play. In our study, many idiosyncratic gestures failed to meet the criterion of intentional usage, and much idiosyncratic gesturing was indeed made in solitary circumstances rather than socially. Tanner noted that several of the gestures made idiosyncratically in her study (and not found in ours) had nevertheless been described before. These included 'circle hands' (only Zura in Tanner's study, but noted in the wild by Schaller 1963), 'foot back' and 'hands behind back' (only Zura in Tanner's study, but seen before at other zoos), 'head turn' (only Kubie in Tanner's study, described before in several zoos and in the wild by Schaller 1963). In addition, 'hands on shoulder' was unique to Kubie in Tanner's study, but appears to match hand on in our work. The remaining eight idiosyncratic gestures ('facewipe', 'finger down lips', 'go', 'hand between legs', 'hide playface', 'mouth/lips', 'teeth', 'wrist glance') were unique to Zura, a female who spent much time engaged in solitary gesturing. Since we studied groups at four separate sites, we had more data with which to refute the hypothesis of idiosyncrasy. For instance, one of the three gestures Pika et al. (2003) observed only at Apenheul, 'object drum', closely resembles our drum object (palms), which we found at several sites. We conclude that differences between studies are largely a result of difficulties in analysis stemming from fundamental qualities of the gorilla's repertoire: namely, that the potential repertoire is extremely large, and that many gestures are used only rarely. The degree of idiosyncrasy is therefore always likely to be overestimated, especially in shorter studies and those restricted to one or a few sites. True idiosyncrasy is relatively rare, and may be associated more with solitary, playful gesturing than intentionally communicative contexts.

Most gestures, therefore, were distributed in a way consistent with a universal, species-typical repertoire. Where gestures were frequent, most or several members of all gorilla groups used them. Rarer gestures showed a more patchy distribution of use, as would be expected: it may take years to record the full repertoire of a single individual (Byrne and Tanner 2006). However, such a distribution 
might also be consistent with ontogenetic ritualization, provided the normal behaviour whose early stages or intention movements become ritualized is a highly predictable, natural sequence for any individual with a similar goal. For instance, if hitting with one arm is used to initiate a play-fight, the action of arm-raising is a prime candidate for ritualization into a play-initiation signal, whereas the action of patting the top of the head is not. Thus, the extent to which intentional gestures are related in form to actions that achieve the effects non-communicatively, or to intention movements regularly associated with them, is a critical issue for the theory of ontogenetic ritualization.

We therefore examined the precise form of each gesture, dividing gestures into (1) those whose form suggested or was at least consistent with intention movements and actions that would achieve the desired effect non-communicatively, and (2) those where the form was entirely different. In the latter case, we found that the gesture usually resembled a species-typical communicative display, in full or abbreviated form. We then examined whether these classes differed in the signaller's adjustment to the attentional state of the audience. Was the gesture modality appropriate for the audience's ability to perceive the gesture, with attention paid to the gaze direction of the recipient especially in the case of silent visual gestures, and tactile gestures associated more with cases where the recipient would be unable to see a distal movement? The two categories did not differ in these ways. For both gesture classes, silent visual gestures were given overwhelmingly to individuals who were already looking, audible gestures slightly less so, and tactile gestures less still, although even they were used more often to individuals whose attention was focused upon the signaller. Similarly, no qualitative difference was found in the degree of flexibility of the two gesture classes: both were used in many situational contexts, and a range of each might be used in a single context. Gestures whose form was consistent with acquisition by ritualization were used in a slightly larger number of contexts on average, and in some contexts species-typical gestures were less used, but the differences were small. Just the same applied to gestural 'meaning', in the sense of the goal to which gesture use appears directed and whose accomplishment apparently satisfied the gesturer. Gorilla gestures are multi-functional, each typically used for several overlapping purposes, but the pattern of functions is characteristic of the individual gesture and not markedly different at different sites, for both species-typical and potentially ritualized gestures. Attention getting was identified as a function for only a minority of cases for any of the gestures examined in detail.

We also failed to detect other possible diagnostics of ontogenetic ritualization. The theory is essentially dyadic: it is the behavioural interaction between two familiar companions that serves to build up each new action as a communicative gesture. The resulting communication should, then, sometimes have a dyadic character. Evidence that a particular gesture was used mainly with one other partner would be supportive of its origin by ontogenetic ritualization, but we found only one such case, and for this the other participant was a human caretaker. In principle, an individual might have learnt, by ontogenetic ritualization, to use quite different gestures to achieve the same ends when interacting with different partners. Signals derived by ontogenetic ritualization are one-way signals, and only by coincidence might one expect both participants to use an identical gesture for the same purpose to each other. Evidence that members of a dyad typically use different signals to each other for an identical purpose would be strongly supportive of ontogenetic ritualization. We found none. In the typical case, both members of a communicating dyad were able to use the same gesture for the same purpose: repertoires were extensively shared.

Some of these findings might have resulted even if ontogenetic ritualization were the major means of acquisition of gestures in gorillas. For instance, a single agent might sometimes use similar behavioural sequences with several partners, on different occasions. As a result, each partner might begin to interpret the same action of the agent as a communicative signal. Moreover, some patterns of behaviour are likely to be highly consistent across individuals, regardless of their previous experience and social group composition. In these cases, ontogenetic ritualization might well result in similar gestural forms becoming used for similar functions in different individuals in different groups. But it is stretching coincidence to believe that this should almost always happen; and that no sign of an origin in dyadic mutual reinforcement should ever be found; and that idiosyncratic uses of gesture should be a rarity.

We conclude, therefore, that it is unsafe to attempt categorization of great ape gestures into a (cognitively uninteresting) species-typical, "innate" repertoire of gestures used inflexibly, and a repertoire of learned (and often idiosyncratic) gestures deployed flexibly and intentionally. All groups of Western Gorillas we studied showed very extensive and broadly overlapping repertoires of intentionally used gestures. Pika (2007a, b) likewise noted "high levels of agreement concerning the performance of gestures between groups". She concluded that this was entirely consistent "with the hypothesis of Tomasello and Call (1997), who claimed that apes acquire their gestures via an individual learning process called ontogenetic ritualization". We cannot agree, for the case of the gorilla. Instead, we consider the only reasonable conclusion is that 
the great majority of gorilla gestures are part of a speciestypical repertoire, albeit one of unusually large size.

This conclusion does not render gorilla or other great ape gestural communication a less interesting object of study. These gestures are used intentionally in a flexible, goal-directed way, with clear account taken of the attentional state of the audience. In these characteristics, they are thus very unlike the more automatic bodily signals described for many species of mammal, and more like some forms of human non-verbal communication. Rather, an intriguing parallel may be drawn with human facial expressions, which similarly appear to be hard-wired and universal across cultures (Ekman and Friesen 1971), and yet are flexibly deployed in cognitively sophisticated ways that differ among individuals and cultures. Moreover, although the general function of each gesture is apparently species-typical, how gorillas use their gestures is undoubtedly modified by contextual learning (Janik and Slater 1997), just as the functional referents of biologically fixed vocalizations are refined by experience in monkeys (Seyfarth and Cheney 1986; see Pika et al. 2003 for a similar conclusion). And the characterization of an individual ape's gestural repertoire as a subset of a very extensive, biologically determined species repertoire is intriguingly different to most other animal communication systems, although entirely consistent with how great apes perform 'gestural imitation' (Byrne and Tanner 2006).

It remains a puzzle that gorillas do not regularly extend the repertoire of gestures given them by biology. There seems little doubt that their motor control (Byrne et al. 2001) and social learning capacities (Stoinski et al. 2001) are sufficient for this to be possible. Even monkeys, with much less cortical control of manual action, have been found able to invent gestures and local cultural traditions have been described (Laidre 2008; Perry et al. 2003; Perry and Manson 2003). Local traditions of use of particular gestures have been noted repeatedly in great apes (Ingmanson 1987; McGrew and Tutin 1978; Nishida 1986; van Schaik et al. 2003; Whiten et al. 1999). Given human help gorillas and other apes can acquire an extensive vocabulary of novel gestures, and use many of them referentially (Patterson and Linden 1981), and the very limited signs of culturally learnt gesture in gorillas suggest that the possibility exists under natural conditions. We can only conclude that gorillas fail to 'see the point' of inventing new gestures to refer to novel situations: a limitation on imagination, rather than communication.

Acknowledgments This work was conducted as part of the European Commission Sixth Framework Programme "Origins of Referential Communication", contract 12787 . We thank the Ministry of Forest Economy and the staff of the Wildlife Conservation Society for permission to work at Mbeli Bai, Congo, and in particular Emma Stokes and Mark Gately for crucial logistical support, and Joel Glick for help in the field. We are grateful to Basel and Zürich Zoos, Switzerland, and to La Vallée des Singes, France, for allowing us to study their excellent gorilla groups, and especially to Jakob Huber at Basel, Robert Zingg at Zürich, and Jan Vermeer at La Vallée, who gave us help throughout. Joanne Tanner, Simone Pika, Juan Carlos Gómez, Erica Cartmill and Klaus Zuberbühler have given us much helpful advice and stimulating discussion, and Simone Pika and Joanne Tanner in particular kindly read and commented upon the whole manuscript. Three anonymous referees provided very useful suggestions for improving the manuscript.

\section{Appendix}

Table 5

Table 5

\begin{tabular}{|c|c|c|c|}
\hline Gesture name & Description & $\begin{array}{l}\text { Tanner and } \\
\text { Byrne (1999) }\end{array}$ & $\begin{array}{l}\text { Pika et al. } \\
(2003)\end{array}$ \\
\hline \multicolumn{4}{|l|}{ Visible only } \\
\hline 1-handed move object & $\begin{array}{l}\text { Grabbing an object with one hand and moving it away or pulling it } \\
\text { forcefully }\end{array}$ & & \\
\hline 2-handed move object & $\begin{array}{l}\text { Grabbing an object with both hands and moving it away or pulling it } \\
\text { forcefully }\end{array}$ & & Move \\
\hline Arm raise & Raising one arm above the head & Up & Reach \\
\hline Arm shake & Shaking loosely one arm from shoulder joint & Armshake & Arm shake \\
\hline Arm swing & Swinging arm back and forth on side, either once or repetitively & Down & \\
\hline Arm swing under & Swinging arm back and forth from front of body to between legs & Arm swing under & \\
\hline $\begin{array}{l}\text { Arm swing under with } \\
\text { object }\end{array}$ & $\begin{array}{l}\text { Swinging arm back and forth from front of body to between legs while } \\
\text { holding an object in hand }\end{array}$ & & \\
\hline Arm swing with object & $\begin{array}{l}\text { Swinging arm back and forth on the side, either once or repetitively } \\
\text { while holding an object in hand }\end{array}$ & & \\
\hline Arms raise & Raising both arms above the head & & Chuck up \\
\hline Arms shake & Shaking loosely both arms from shoulder joints & Armshake & Arm shake \\
\hline
\end{tabular}


Table 5 continued

\begin{tabular}{|c|c|c|c|}
\hline Gesture name & Description & $\begin{array}{l}\text { Tanner and } \\
\text { Byrne (1999) }\end{array}$ & $\begin{array}{l}\text { Pika et al. } \\
(2003)\end{array}$ \\
\hline Arms swing & Swinging arms in front of body from one side to the other & & \\
\hline Arms swing with object & $\begin{array}{l}\text { Swinging arms in front of body from one side to the other while } \\
\text { holding object(s) in hand(s) }\end{array}$ & & \\
\hline Arms wave & Waving arms raised above head & & \\
\hline Bipedal run/walk & Running or walking bipedally & & \\
\hline Bipedal stance & Standing upright on two legs & & \\
\hline Bite wrist + arm shake & Biting wrist of one hand while shaking loosely the opposite arm & & \\
\hline Body drum & Drumming own body part with fists & Chest knock & \\
\hline Body tapping & Tapping own body part repetitively with palm of hand & & \\
\hline Body tapping with object & $\begin{array}{l}\text { Tapping own body part repetitively with palm of hand and an object } \\
\text { placed between hand and body }\end{array}$ & & \\
\hline Bounce & $\begin{array}{l}\text { Standing on four relaxed limbs and performing rapid up and down } \\
\text { movements }\end{array}$ & & \\
\hline Bow & $\begin{array}{l}\text { Bending forward upper body according to the body } x \text { axis while } \\
\text { standing on two legs }\end{array}$ & & Bow \\
\hline Chest beat play & Drumming playfully on chest with palm of hands & & \\
\hline Disco arms shake & Shaking arms in a rotating movement towards self on one side of head & & \\
\hline Feet shake & Shaking feet loosely & & \\
\hline Gallop & $\begin{array}{l}\text { Running with forelegs playfully stamping the floor (similar to a child } \\
\text { imitating a horse galloping) }\end{array}$ & & Gallop \\
\hline Hand shake & Shaking hand loosely from wrist joint & Armshake & Arm shake \\
\hline Hand shake with object & Shaking hand loosely from wrist joint while holding an object in hand & & \\
\hline Hands shake & Shaking loosely both hands from wrist joints & Armshake & Arm shake \\
\hline Hands shake with object & $\begin{array}{l}\text { Shaking loosely both hands from wrists joints while holding object in } \\
\text { hands }\end{array}$ & & \\
\hline Head nod & Nodding head up and down in the body $x$ axis & Head nod & Bow \\
\hline Head rub & Rubbing head back and forth with palm of hands and/or forearms & & \\
\hline Head shake & Shaking head from side to side on horizontal axis & Head shake & Bow \\
\hline Head shake with object & Shaking head from side to side with object in the mouth & Head twirl & Bow \\
\hline Ice skating & $\begin{array}{l}\text { Twirling movement of whole body around the body } y \text { axis while } \\
\text { standing on four legs usually with head bent forward }\end{array}$ & & Ice skating \\
\hline Jump & Jumping from one location to another or springing on location & & Jump \\
\hline Leg rub & $\begin{array}{l}\text { Rubbing extended legs back and forth with palm of hands while } \\
\text { sitting }\end{array}$ & & \\
\hline Leg swing & Swinging leg back and forth & & \\
\hline Lick hand & Licking palm of hand frantically and repetitively & & \\
\hline Look & Staring intensively at another individual for several seconds & & \\
\hline Multiple stamp & Stamping the ground repetitively with foot, fast motion & & \\
\hline Multiple stamp, 2 feet & $\begin{array}{l}\text { Stamping the ground repetitively with both feet alternatively, fast } \\
\text { motion }\end{array}$ & & Stamp \\
\hline Object on head & Putting an object (usually straw or leaves) on head & & \\
\hline Pirouette & $\begin{array}{l}\text { Twirling movement of whole body around the body } y \text { axis while } \\
\text { standing on four legs. Progressive forward movement in space }\end{array}$ & & \\
\hline Pirouette with object & $\begin{array}{l}\text { Twirling forward movement of whole body around the body } y \text { axis } \\
\text { while standing on four legs. with an object held in mouth or } \\
\text { covering body }\end{array}$ & & \\
\hline Push object & Pushing away forcefully an object with hand & & \\
\hline Reach & Extending one arm towards another individual & Away & Reach \\
\hline Rocking & Rocking movement of whole body usually while seated & & \\
\hline Rope spinning & $\begin{array}{l}\text { Twirling whole body very rapidly around the y body axis, while } \\
\text { hanging to a rope with one or two hands and one or two feet }\end{array}$ & & \\
\hline
\end{tabular}


Table 5 continued

\begin{tabular}{|c|c|c|c|}
\hline Gesture name & Description & $\begin{array}{l}\text { Tanner and } \\
\text { Byrne (1999) }\end{array}$ & $\begin{array}{l}\text { Pika et al. } \\
(2003)\end{array}$ \\
\hline Shake object & Shaking fixed object forcefully with both hands & & Object shake \\
\hline Side roulade & $\begin{array}{l}\text { Twirling side movement of whole body around body } y \text { axis while } \\
\text { laying on the floor }\end{array}$ & & \\
\hline Single body tap & Slapping body part singly with palm of hand (except chest) & & Body slap \\
\hline Somersault & Twirling forward movement of whole body around the body $x$ axis & & Somersault \\
\hline Stiff gallop & Running with stiff forelegs & & \\
\hline Stiff stance & $\begin{array}{l}\text { Standing rigidly with stiff limbs and forelimbs held tight, facial } \\
\text { expression of tight lips usually occurs in sexual context }\end{array}$ & & Stiff stance \\
\hline Stiff walk & Walking with rigid forelegs and usually head tilted on the side & & \\
\hline Stamp & $\begin{array}{l}\text { Stamping the ground forcefully with sole of foot, often following or } \\
\text { simultaneous to a chest beat }\end{array}$ & & Stamp \\
\hline Stamp, 2-feet & Stamping the ground forcefully with sole of feet & & \\
\hline Straw wave & Throwing straw over head with both hands & & Straw wave \\
\hline Tapping contralateral & $\begin{array}{l}\text { Tapping shoulders or elbows repetitively and simultaneously with } \\
\text { palm of hands and crossed arms }\end{array}$ & Arm cross & \\
\hline Throw object & Throwing away an object towards another individual & & Throw \\
\hline Throw threat & $\begin{array}{l}\text { Grabbing an object and performing a forward and forceful movement } \\
\text { towards an individual }\end{array}$ & & \\
\hline \multicolumn{4}{|l|}{ Audible and visible } \\
\hline 1-handed chest beat & Tapping chest repetitively with cupped hand & Chest pat & \\
\hline Body beat & $\begin{array}{l}\text { Drumming body part (except chest) with cupped hands or palm of } \\
\text { hands }\end{array}$ & $\begin{array}{l}\text { Body beat/beat sides of } \\
\text { head }\end{array}$ & Body beat \\
\hline Body beat with object & $\begin{array}{l}\text { Drumming body part (except chest) with cupped hands or palm of } \\
\text { hands with an object placed between hands and body part }\end{array}$ & & \\
\hline Chest beat & Drumming chest with cupped hands & Chest beat & Chest beat \\
\hline Chest beat with object & $\begin{array}{l}\text { Drumming chest with cupped hands and an object placed between } \\
\text { hands and chest }\end{array}$ & & \\
\hline Clap & Tapping both palms of hands against each other as human applause & Clap & Clap \\
\hline Drum object (fists) & Drumming an object with fists & & \\
\hline Drum object (palms) & Drumming an object with palm of hands & & \\
\hline Knock object & Hitting an object forcefully and multiply with fist or wrist & Knock & Slap ground \\
\hline $\begin{array}{l}\text { Multiple stamp, 2-feet on } \\
\text { object }\end{array}$ & $\begin{array}{l}\text { Stamping an object repetitively with both feet alternatively, fast } \\
\text { motion }\end{array}$ & & \\
\hline Punch object & Hitting object forcefully and singly with fist or wrist & Backhand pound & Slap ground \\
\hline Slap object, 1-handed & Slapping forcefully and singly object with palm of hand & Slap surface & Slap ground \\
\hline Slap object, 2-handed & Slapping forcefully and singly object with palm of hands & & \\
\hline Stamp 2-feet, on object & Stamping an object forcefully with sole of feet & & \\
\hline Stamp object & $\begin{array}{l}\text { Stamping an object forcefully with sole of foot, often following or } \\
\text { simultaneous to a chest beat }\end{array}$ & & Stamp \\
\hline Tapping object & Tapping an object repetitively with palm of hand & & \\
\hline Water splash & Hitting water with hands or fists & & \\
\hline \multicolumn{4}{|l|}{ Tactile } \\
\hline 2-handed grab & Grabbing another individual's body part with two closed hands. & & \\
\hline 2-handed grab-pull & $\begin{array}{l}\text { Grabbing another individual's body part with both closed hands and } \\
\text { pulling towards self }\end{array}$ & & \\
\hline Bite & $\begin{array}{l}\text { Gentle biting of another individual's body part, different from } \\
\text { aggressive biting }\end{array}$ & Bite & Formal bite \\
\hline Bite + arms shake on & $\begin{array}{l}\text { Biting other individual (usually its head) and shaking arms on the } \\
\text { other's body }\end{array}$ & & \\
\hline
\end{tabular}


Table 5 continued

\begin{tabular}{|c|c|c|c|}
\hline Gesture name & Description & $\begin{array}{l}\text { Tanner and } \\
\text { Byrne (1999) }\end{array}$ & $\begin{array}{l}\text { Pika et al. } \\
(2003)\end{array}$ \\
\hline Drum other & Drumming another individual with palms of hands & & \\
\hline Embrace & $\begin{array}{l}\text { Embracing another individual by wrapping both arms around its body, } \\
\text { usually reciprocal }\end{array}$ & & Embrace \\
\hline Grab-pull & $\begin{array}{l}\text { Grabbing another individual's body part with one closed hand and } \\
\text { pulling towards self }\end{array}$ & Tactile close & $\begin{array}{l}\text { Grab-push- } \\
\quad \text { pull }\end{array}$ \\
\hline Hand on & $\begin{array}{l}\text { Touching head of another individual with palm of hand and } \\
\text { maintaining touch for several seconds }\end{array}$ & Tactile close & Hand on \\
\hline Hands on & $\begin{array}{l}\text { Touching head of another individual with palm of both hands and } \\
\text { maintaining touch for several seconds }\end{array}$ & & \\
\hline Hit with object & Hitting another individual with object held in hand & & \\
\hline Kick & Kicking another individual with foot & & \\
\hline One-handed grab & Grabbing another individual's body part with one closed hand & Tactile close & Grab \\
\hline Poke & Touching repetitively other individual's body part with finger & & \\
\hline Positioning & $\begin{array}{l}\text { Pushing or pulling lightly then releasing another individual's limb in } \\
\text { the direction of desired position, usually used in grooming }\end{array}$ & Tactile close & \\
\hline Pounce & Jumping forward on another individual & & \\
\hline Punch & Hitting another individual forcefully and singly with fist or wrist & & Punch \\
\hline Push, 1-handed & Pushing away another individual with hand or arm & Tactile close & \\
\hline Push, 2-handed & Pushing away forcefully another individual with two hands & & Push \\
\hline Slap other & Slapping forcefully and singly another individual with palm of hand & & Slap \\
\hline Slap other, 2-handed & Slapping forcefully and singly another individual with palm of hands & & \\
\hline Stroking & $\begin{array}{l}\text { Stroking another individual with gentle back and forth movement of } \\
\text { palm of hand }\end{array}$ & Tactile close & \\
\hline Tandem walk & Two individuals walk together, one individual over the other one & & \\
\hline Tapping other & Tapping repetitively another individual with palm of hand & Tap other & Prod \\
\hline Touch & Touching gently another individual's body part with palm of hand & Tactile close & $\begin{array}{l}\text { Touch/long } \\
\text { touch }\end{array}$ \\
\hline
\end{tabular}

\section{References}

Arnold K, Zuberbühler K (2006) Semantic combinations in primate calls. Nature 441:303

Arnold K, Zuberbühler K (2008) Meaningful call combinations in a non-human primate. Curr Biol 18:R203-R203

Bates E, Benigni L, Bretherton I, Camaioni L, Volterra V (1979) The emergence of symbols. Academic Press, New York

Breuer T, Breuer-Ndoundou Hockemba M, Olejniczak C, Parnell RJ, Stokes EJ (2009) Physical maturation, life-history classes and age estimates of free-ranging western gorillas-insights from Mbeli Bai, Republic of Congo. Am J Primatol 71:106-119

Bruner JS (1972) Nature and uses of immaturity. Am Psychol 27:687-708

Byrne RW, Tanner JE (2006) Gestural imitation by a gorilla: evidence and nature of the phenomenon. Int J Psychol Psychol Ther 6:215-231

Byrne RW, Corp N, Byrne JM (2001) Manual dexterity in the gorilla: bimanual and digit role differentiation in a natural task. Anim Cognit 4:347-361

Call J, Tomasello M (2007a) Comparing the gestures of apes and monkeys. In: Call J, Tomasello M (eds) The gestural communication of apes and monkeys. Lawrence Erlbaum Associates, Mahwah, pp 197-220
Call J, Tomasello M (2007b) The gestural communication of apes and monkeys. Lawrence Erlbaum Associates, Hillsdale

Call J, Tomasello M (2007c) The gestural repertoire of chimpanzees (Pan troglodytes). In: Call J, Tomasello M (eds) The gestural communication of apes and monkeys. Lawrence Erlbaum Associates, Mahwah, pp 17-39

Cartmill EA, Byrne RW (2007) Orangutans modify their gestural signalling according to their audience's comprehension. Curr Biol 17:1345-1348

Cheney DL, Seyfarth RM (1990) How monkeys see the world: inside the mind of another species. University of Chicago Press, Chicago

Cheney DL, Seyfarth RM (1996) Function and intention in the calls of non-human primates. Proc British Acad 88:59-76

Darwin C (1872) The expression of the emotions in man and animals. John Murray, London

de Waal FBM, Seres M (1997) Propagation of handclasp grooming among captive chimpanzees. Am J Primatol 43:339-346

del Hoyo J, Elliott A, Sargatal J (1996) Handbook of the birds of the world. Volume 3 Hoatzin to Auks. Lynx Editions, Barcelona

Eibl-Eibesfeldt I (1972) Similarities and differences between cultures in expressive moments. In: Hinde RA (ed) Non-verbal communication. Cambridge University Press, Cambridge, pp 297-312 
Ekman P, Friesen WV (1971) Constraints across culture in the face and emotion. J Pers Soc Psychol 17:124-129

Gardner RA, Gardner BT, Van Cantfort TE (1989) Teaching sign language to chimpanzees. SUNY Press, New York

Hauser MD (1992) Costs of deception: cheaters are punished in rhesus monkeys (Macaca mulatta). Proc Natl Acad Sci USA 89:12137-12139

Hauser MD (1996) The evolution of communication. MIT Press, Cambridge

Hauser MD, Chomsky N, Fitch WT (2002) The faculty of language: what is it, who has it, and how did it evolve? Science 298:1569_ 1579

Hayes C (1951) The ape in our house. Harper, New York

Hockett CF (1960) Logical considerations in the study of animal communication. In: Lanyon WE, Tavolga WN (eds) Animal sounds and communication. American Institute of Biological Sciences, Washington, pp 392-430

Ingmanson EJ (1987) Clapping behavior: non-verbal communication during grooming in a group of captive pygmy chimpanzees. Am J Phys Anthropol 72:173-174

Janik VM, Slater PJB (1997) Vocal learning in mammals. Adv Study of Behav 26:59-99

Kellogg WN, Kellogg LA (1933) The Ape and the Child. McGrawHill, New York

King BJ (2004) The dynamic dance: nonvocal communication in African great apes. Harvard University Press, Cambridge

Laidre ME (2008) Do captive mandrills invent new gestures? Anim Cognit 11:178-187

Leavens DA, Russell JL, Hopkins WD (2005) Intentionality as measured in the persistence and elaboration of communication by chimpanzees (Pan troglodytes). Child Dev 76:291-306

Liebal K (2007) Gestures in orangutans. In: Call J, Tomasello M (eds) The gestural communication of apes and monkeys. Lawrence Erlbaum Associates, Mahwah, pp 69-98

Liebal K, Call J, Tomasello M (2004) The use of gesture sequences in chimpanzees. Am J Primatol 64:377-396

McGrew WC, Tutin CEG (1978) Evidence for a social custom in wild chimpanzees? Man 13:234-251

Miles H (1990) The cognitive foundations for reference in a signing orangutan. In: Parker S, Gibson K (eds) "Language" and intelligence in monkeys and apes. Cambridge University Press, Cambridge, pp 511-539

Nishida T (1980) The leaf-clipping display: a newly discovered expressive gesture in wild chimpanzees. J Hum Evol 9:117-128

Nishida T (1986) Local traditions and cultural transmission. In: Smuts BB, Cheney DL, Seyfarth RM, Wrangham RW, Struhsaker TT (eds) Primate societies. University of Chicago Press, Chicago, pp 462-474

Owren M, Rendall D (1997) An affect-conditioning model of nonhuman primate vocal signaling. Perspect Ethol 12:299-346

Parnell RJ (2002) Group size and structure in western lowland gorillas (Gorilla gorilla gorilla) at Mbeli Bai, Republic of Congo. Am J Primatol 56:193-206

Patterson F, Linden E (1981) The education of Koko. Holt Rinehart and Winston, New York

Perry S, Manson JH (2003) Traditions in monkeys. Evolut Anthropol 12:71-81

Perry S, Baker M, Fedigan L, Gros-Louis J, Jack K, MacKinnon KC, Manson JH, Panger M, Pyle K, Rose L (2003) Social conventions in wild white-faced capuchin monkeys. Evidence for traditions in a neotropical primate. Curr Anthropol 44:241-268

Pika S (2007a) Gestures in subadult bonobos (Pan paniscus). In: Call J, Tomasello $M$ (eds) The gestural communication of apes and monkeys. Lawrence Erlbaum Associates, Mahwah, pp 41-67
Pika S (2007b) Gestures in subadult gorillas (Gorilla gorilla). In: Call J, Tomasello M (eds) The gestural communication of apes and monkeys. Lawrence Erlbaum Associates, Mahwah, pp 99-130

Pika S, Liebal K, Tomasello M (2003) Gestural communication in young gorillas (Gorilla gorilla): gestural repertoire, learning, and use. Am J Primatol 60:95-111

Pollick AS, de Waal FBM (2007) Ape gestures and language evolution. Proc Natl Acad Sci 104:8184-8189

Poss SR, Kuhar C, Stoinski TS, Hopkins WD (2006) Differential use of attentional and visual communicative signaling by orangutans (Pongo pygmaeus) and gorillas (Gorilla gorilla) in response to the attentional status of a human. Am J Primatol 68:978-992

Ristau C (1991) Aspects of the cognitive ethology of an injuryfeigning bird, the piping plover. In: Ristau $C$ (ed) Cognitive ethology: the minds of other animals. Lawrence Erlbaum Associates, Hillsdale, pp 91-126

Schaller GB (1963) The mountain gorilla. Chicago University Press, Chicago

Seyfarth RM, Cheney DL (1986) Vocal development in vervet monkeys. Animal Behav 34:1640-1658

Smith WJ (1965) Message, meaning and context in ethology. Am Nat 99:405-409

Stoinski TS, Wrate JL, Ure N, Whiten A (2001) Imitative learning by captive western lowland gorillas (Gorilla gorilla gorilla) in a simulated food-processing task. J Comp Psychol 115:272-281

Tanner J (1998) Gestural communication in a group of zoo-living lowland gorillas. Ph.D. thesis. University of St Andrews, St Andrews (unpublished)

Tanner JE, Byrne RW (1993) Concealing facial evidence of mood: evidence for perspective-taking in a captive gorilla? Primates 34:451-456

Tanner JE, Byrne RW (1996) Representation of action through iconic gesture in a captive lowland gorilla. Curr Anthropol 37:162-173

Tanner JE, Byrne RW (1999) The development of spontaneous gestural communication in a group of zoo-living lowland gorillas. In: Parker ST, Mitchell RW, Miles HL (eds) The mentalities of gorillas and orangutans. Comparative perspectives. Cambridge University Press, Cambridge, pp 211-239

Tomasello M (1996) Do apes ape? In: Heyes CM, Galef BG (eds) Social learning in animals: the roots of culture. Academic Press, San Diego, pp 319-346

Tomasello M, Call J (1997) Primate cognition. Oxford University Press, New York

Tomasello M, Call J (2007) Intentional communication in nonhuman primates. In: Call J, Tomasello M (eds) The gestural communication of apes and monkeys. Lawrence Erlbaum Associates, Mahwah, pp 1-15

Tomasello M, George B, Kruger A, Farrar J, Evans E (1985) The development of gestural communication in young chimpanzees. J Hum Evol 14:175-186

Tomasello M, Gust D, Frost TA (1989) A longitudinal investigation of gestural communication in young chimpanzees. Primates 30:35-50

Tomasello M, Call J, Nagell C, Olguin R, Carpenter M (1994) The learning and use of gestural signals by young chimpanzees: a trans-generational study. Primates 35:137-154

van Schaik CP, Ancrenaz M, Borgen G, Galdikas B, Knott CD, Singleton I, Suzuki A, Utami SS, Merrill M (2003) Orangutan cultures and the evolution of material multure. Science 299:102105

Vygotsky L (1962) Thought and language. MIT Press, Cambridge

Whiten A, Goodall J, McGrew WC, Nishida T, Reynolds V, Sugiyama Y, Tutin CEG, Wrangham RW, Boesch C (1999) Cultures in chimpanzees. Nature 399:682-685 